\title{
O ALIMENTO COMO CATEGORIA HISTÓRICA: SABERES E PRÁTICAS ALIMENTARES NA REGIÃO DO VALE DO RIO PARDO (RS/BRASIL)
}

\author{
Food as a historical category: knowledge and food \\ practices in the region of Vale do Rio \\ Pardo(RS/Brazil)
} Everton Luiz Simon ${ }^{*}$ e Éder da Silva Silveira ${ }^{* *}$

\begin{abstract}
RESUMO
O presente artigo realiza um exercício de caracterização de alguns costumes alimentares da Região do Vale do Rio Pardo/RS - Brasil, bem como apresenta uma revisão e reflexão sobre a análise realizada por Simon (2014) ao tentar perceber a influência ou a presença de características dos modelos alimentares "romano" e "bárbaro" em hábitos alimentares de descendentes de alemães e italianos nessa região. Além de pesquisa bibliográfica e documental, fez parte da metodologia o trabalho a observação in loco, e a realização de entrevistas semiestruturadas com 39 sujeitos qualificados nas comunidades regionais investigadas. Considera-se que a identificação dessas características na culinária regional de colonos alemães e italianos no Sul do Brasil devem ser vistas na perspectiva de um processo complexo e intercultural que não se reduz aos modelos alimentares romano e bárbaro, mas, sim, que ocorrem em diferentes processos de integração e adaptação.
\end{abstract}

Palavras chave: História da Alimentação; modelos alimentares; culinária regional.

* Doutorando em História na Universidade do Vale do Rio dos Sinos - Unisinos Bolsista Capes - Prosup. Professor do curso de Gastronomia da Universidade de Santa Cruz do Sul - Departamento de história e geografia.

** Professor do Progama de Pós-Graduação em Educação e do Departamento de história e geografia da Universidade de Santa Cruz do Sul - UNISC. 


\begin{abstract}
This article conducts an exercise of characterization of some dietary customs in the region of Vale do Rio Pardo/RS - Brazil, as well as presents a review and reflection on the analysis performed by Simon (2014) when trying to understand the influence or presence of characteristics of food templates "Roman" and "barbarian" in feeding habits of descendants of Germans and Italians in this region. In addition to bibliographical and documentary research, took part in the work methodology of participant observation, observation in loco, and semi-structured interviews with 39 subjects qualified regional communities investigated. It is considered that the identification of these characteristics in the regional cuisine of German and Italian settlers in southern Brazil should be seen in the perspective of a complex process and intercultural which is not reduced to the Roman food models and barbaric, but, yes, that occur in different processes of integration and adaptation.
\end{abstract}

Key words: History of food; food models; regional cuisine.

\title{
Introdução
}

Os temas da comida e da alimentação têm invadido as ciências humanas, especialmente a partir do momento em que se percebeu que o gosto alimentar não resulta exclusivamente dos aspectos nutricionais e biológicos dos alimentos. O termo "comer", diferentemente de "alimentar-se", implica em um ato social, na medida em que constitui e é constitutivo de "atitudes ligadas aos usos, costumes, protocolos, condutas e situações", conforme salientou Carlos Antunes dos Santos ${ }^{1}$. Na perspectiva apresentada por Santos, a qual compartilhamos, o alimento constitui uma categoria histórica, pois carrega vestígios dos padrões de permanências e mudanças dos hábitos e das práticas alimentares, referenciais importantes da cultura humana.

1 SANTOS, Carlos Roberto Antunes dos. A alimentação e seu lugar na História: os tempos da memória gustativa. In: História: Questões \& Debates (UFPR), Curitiba, n. 42, p. 11-31, 2005 , p. 12 . 
O presente texto insere-se no campo da história da alimentação e seu tema está relacionado à formação dos hábitos alimentares da região do Vale do Rio Pardo, localizada no sul do Brasil. A partir das discussões realizadas por nós no grupo de estudo e pesquisa recentemente constituído no departamento ao qual estamos vinculados em nossa universidade ${ }^{2}$, buscaremos apresentar aspectos relevantes do estudo realizado por um de nós ${ }^{3}$, que compreendeu o papel da alimentação e da culinária no contexto do desenvolvimento regional. Trata-se de um exercício de caracterização de alguns costumes alimentares dessa região, bem como de uma revisão e reflexão sobre a análise realizada por Simon (2014) ao tentar perceber a influência ou a presença dos modelos alimentares "romano" e "bárbaro" em hábitos alimentares de descendentes de alemães e italianos na referida região.

De acordo com a pesquisa de Simon (2014), com os movimentos de colonização do Sul do Brasil, ocorridos no século XIX, imigrantes alemães e italianos teriam trazido para a Região do Vale do Rio Pardo traços culturais e hábitos alimentares de suas regiões de origem. Esses traços, segundo o estudo, carregariam influências e características dos dois modelos alimentares que marcaram a Europa durante séculos, os modelos dos povos romanos e bárbaros, respectivamente. Esse artigo pretende refletir sobre os limites e possibilidades da relação estabelecida naquele momento, onde defendeu-se que, ao colonizarem regiões no sul do Brasil, alemães e italianos trouxeram influências desses dois modelos, as quais, ao longo do tempo, mesclaram-se com outras, como as de indígenas e negros, originando a chamada "culinária regional ${ }^{4}$ ".

2 Trata-se de um grupo vinculado ao projeto de pesquisa "Entre o garfo e a pena: trabalho e alimentação no Vale do Rio Pardo nos registros de viajantes europeus do século XIX", em desenvolvimento na Universidade de Santa Cruz do Sul.

3 SIMON, Everton Luiz Culinária regional: história, saberes e identidade regional no Vale do Rio Pardo/RS - Brasil / Everton Luiz Simon. - 2014. 118 f. : il. ; 30 cm. Dissertação (Mestrado em Desenvolvimento Regional) - Universidade de Santa Cruz do Sul, 2014. Orientadora: Prof $^{a}$. Dr ${ }^{\mathrm{a}}$. Virgínia Elisabeta Etges.

4 "São processos de lentas fusões e mestiçagens, desencadeadas nas áreas fronteiriças e, depois, arraigadas nos territórios como emblemas de autenticidade local, mas cuja natureza é sempre hibrida e múltipla”. MONTANARI, Massimo. Comida como cultura. 2. ed. São Paulo: SENAC-SP, 2013, p.11. 
Para estudar as influências dos modelos alimentares trazidos pelos imigrantes europeus, na formação de marcas identitárias na culinária da região do Vale do Rio Pardo, Simon optou pela pesquisa de campo, com observação in loco, bem como com a coleta de dados secundários e realização de entrevistas semiestruturadas. Foram realizadas 39 entrevistas com informantes qualificados, indicados por Clubes de mães, Grupos de terceira idade, Grupos de manifestações culturais, como o Centro Cultural Vinte Cinco de Julho (Alemães) e o Círculo Cultural Bella Itália (Italianos); também foram entrevistados informantes indicados por outras instituições, como Grupos da Ordem Auxiliadora das Senhoras Evangélicas - OASE; Empresa de Assistência Técnica e Extensão Rural do Governo do Estado Rio Grande do Sul - EMATER/RS e o Centro de Apoio ao Pequeno Agricultor - CAPA; além da indicação dos próprios sujeitos das comunidades regionais. A metodologia que deu suporte às entrevistas esteve baseada em roteiros que consideraram aportes relativos à metodologia da História Oral e, também, às categorias de conteúdo vinculadas às características dos modelos alimentares "romano" e "bárbaro" presentes na obra de Flandrin e Montanari (1998).

Além dos dados coletados nas entrevistas, buscou-se também coletar documentos e informações junto às associações culturais regionais. A coleta desses documentos visou ampliar o conhecimento a partir do cotejamento de fontes e triangulação de dados, como os obtidos no mapeamento e análise de cadernos de receitas, registros fotográficos das famílias, e outros vestígios de saberes e práticas alimentares de imigrantes e seus descendentes. Dessa maneira, foram analisados os conteúdos de variados documentos que revelam, além dos sabores e gostos de uma época, a expressão histórica da região pelo viés da alimentação.

$\mathrm{O}$ texto estará dividido em três partes. $\mathrm{Na}$ primeira, apresentamos uma caracterização do cenário do estudo, a região sulina do Brasil conhecida como "Vale do Rio Pardo". Na segunda, abordamos algumas características e aspectos históricos dos modelos alimentares dos romanos e bárbaros presentes no estudo realizado por Simon (2014). Baseados nesse mesmo estudo, a terceira parte irá caracterizar alguns saberes e práticas alimentares dessa região a partir da pesquisa empírica que o fundamentou. Em seguida, sobretudo a respeito do consumo de cereais e derivados, apresentamos algumas 
conclusões e relativizações a respeito da ideia presente no estudo de Simon de que imigrantes alemães e italianos teriam trazido e difundido características e influências desses modelos alimentares.

\section{A região do Vale do Rio Pardo}

A formação territorial do Vale do Rio Pardo, conforme Klarmann ${ }^{5}$, teve características históricas distintas em seu processo de povoamento, marcada pela presença de diferentes grupos étnicos. Segundo o autor, a região, aos poucos, foi sendo ocupada por colonos $^{6}$ alemães, originando as colônias de Santa Cruz, Monte Alverne e Candelária. De acordo com o Conselho Regional de Desenvolvimento do Vale do Rio Pardo ${ }^{7}$ :

A região povoada pelos imigrantes e descendestes alemães deu origem a vários municípios na parte mais central do Vale do Rio Pardo e influenciou fortemente nos traços culturais da população de Santa Cruz do Sul, Candelária, Vale do Sol, Vera Cruz, Passo do Sobrado, Vale Verde e Sinimbu. A busca por novas terras fez com que os colonos de origem teuta subissem a encosta da serra, terminando por encontrar-se com os habitantes de origem luso-brasileira e italiana. A região setentrional do Vale do Rio Pardo teve boa parte de suas terras ocupadas por descendentes de italianos. A procura por novas terras também determinou que levas de colonos de origem

5 KLARMANN, Herbert. Região e identidade regional: um estudo da espacialidade e representatividade regional no Vale do Rio Pardo. 1999. 189 f. Dissertação (Mestrado) Universidade de Santa Cruz do Sul, 1999.

6 Neste artigo entende-se por colono "um camponês imigrante ou filho de imigrantes europeus" (ZARTH, Paulo Afonso. Do Arcaico ao moderno: o Rio Grande do Sul agrário do século XIX. Ijuí: Ed. Unijuí, 2002, p.173).

7 CONSELHO REGIONAL DE DESENVOLVIMENTO DO VALE DO RIO PARDO (RS). Plano estratégico de desenvolvimento do Vale do Rio Pardo. Santa Cruz do Sul: UNISC, 1998. P.18. 
italiana constituíssem um importante fluxo migratório das regiões de ocupação pioneira do RS em direção a esse espaço. Assim, nos municípios de Boqueirão do Leão, Gramado Xavier, Ibarama, Sobradinho e Arroio do Tigre, apesar da presença de outras origens étnicas, predomina a população de procedência italiana. Tunas, Lagoão, Herveiras e Barros Cassal, apesar de se localizarem no norte do VRP, têm na população de origem luso-brasileira a maioria de seus habitantes. Já na parte meridional do VRP, ou seja, nos municípios de Encruzilhada do Sul, Rio Pardo, Pantano Grande e General Câmara, houve uma forte ligação histórica com a conquista do território, o latifúndio, a criação extensiva do gado, a escravidão e a herança cultural deixada pelos antepassados.

Em Santa Cruz, de acordo com $\operatorname{Vogt}^{8}$, os primeiros colonizadores alemães chegaram a partir de 19 de dezembro de 1849 e "foram assentados no local atualmente denominado de Linha Santa Cruz (Alte Pikade), às margens da Estrada de Cima da Serra", caminho que ligava o entreposto comercial de Rio Pardo aos campos de gado da região de Soledade. O autor ${ }^{9}$ refere que:

De Linha Santa Cruz, a colonização se expandiu na direção de Rio Pardinho, Dona Josefa, Linha Andréas, Sinimbu, Vila Tereza e Ferraz. Uma vez ocupadas as terras devolutas da Colônia, áreas de particulares foram loteadas dando origem, dentre outras, a Rio Pardense, Faxinal de Dentro, Colônia Germânia (Candelária), Entre-Rios, Formosa, Trombudo, Pomerânia, Chaves, Linha João Alves, Cerro Alegre, São João da Serra, Pinheiral, Linha Nova e outras.

8 VOGT, Olgário Paulo. A colonização alemã no Rio Grande do Sul e o capital social. Tese (Doutorado) - Universidade de Santa Cruz do Sul, 2006. P.97.

9 Idem, p.96. 
Roche $^{10}$ destaca que as terras ocupadas pelos imigrantes alemães eram de relevo acidentado e cobertas por densas matas. Para o autor, o desenvolvimento colonial sempre foi muito heterogêneo, e o que certamente contribuiu para a formação de características identitárias do povo, foram fatores tais como a aglutinação dos imigrantes que tinham a mesma origem, que falavam o mesmo dialeto e que praticavam a mesma religião, fatores esses que contribuíram, ainda, para limitar o raio de seu horizonte de vida e a conservar as tradições familiares.

Segundo o Conselho Regional de Desenvolvimento do Vale do Rio Pardo ${ }^{11}$, compõem a região vinte e três municípios que são: Arroio do Tigre; Boqueirão do Leão; Candelária; Encruzilhada do Sul; Estrela Velha; General Câmara; Herveiras; Ibarama; Lagoa Bonita do Sul; Mato Leitão; Pantano Grande; Passa Sete; Passo do Sobrado; Rio Pardo; Santa Cruz do Sul; Segredo; Sinimbu; Sobradinho; Tunas; Vale do Sol; Vale Verde; Venâncio Aires e Vera Cruz.

Etges $^{12}$ afirma que, a partir do ponto de vista histórico e cultural, não se deve pensar em uma região homogênea, considerando-se o fato de que a mesma tem uma tradição histórica fortemente marcada pela presença de luso-brasileiros e pelos imigrantes alemães e italianos. Há também outras características que particularizam a geografia, a economia, os aspectos socioculturais, e as influências históricas advindas dos processos de colonização. É neste amplo espaço que a região se apresenta como um processo de construção de identidade territorial, ultrapassando assim os limites dos municípios constituídos.7

O desenvolvimento, então, pode ser entendido como um processo dinâmico presente no território, com dimensões que a cada momento são construídas e reconstruídas através das relações sociais,

10 ROCHE, Jean. A colonização alemã e o Rio Grande do Sul. Porto Alegre: Globo, v. 2. (Província) 1969

11 CONSELHO REGIONAL DE DESENVOLVIMENTO DO VALE DO RIO PARDO (RS). Plano estratégico de desenvolvimento do Vale do Rio Pardo. Santa Cruz do Sul: UNISC, 2011.

12 ETGES, Virginia E. A região no contexto da globalização: o caso do Vale do Rio Pardo. In: VOGT, O.; SILVEIRA, R. Vale do Rio Pardo: reconhecendo a região. Santa Cruz do Sul: Edunisc, 2001. 
econômicas e ambientais. O desenvolvimento, de acordo com Brandão $^{13}$,

é um processo multifacetado de intensa transformação estrutural resultado de variadas e complexas interações sociais que buscam o alargamento do horizonte de possibilidades de determinada sociedade. Deve promover a ativação de recursos materiais e simbólicos e a mobilização de sujeitos sociais e políticos, buscando ampliar o campo de ação da coletividade, aumentando sua autodeterminação e liberdade de decisão.

Nesse sentido, a promoção do desenvolvimento regional exige dos agentes diretamente envolvidos no processo, e da sociedade como um todo, a definição de um projeto político que aponte o caminho a ser trilhado ${ }^{14}$. Por desenvolvimento regional, Etges ${ }^{15}$ entende "todo um processo de construção amparado na potencialização de capacidades endógenas". Em Benko ${ }^{16}$, encontramos a afirmação de que o desenvolvimento regional volta-se aos problemas da integração regional, e não possui apenas implicações econômicas, mas tem consequências políticas e culturais, tornando a região um produto social, construído pela sociedade nos espaços de vida.

13 BRANDÃO, Carlos. Desenvolvimento, territórios escalas espaciais: levar na devida conta as contribuições da economia política e da geografia crítica para construir a abordagem interdisciplinar. In: RIBEIRO, Maria Teresa Franco; MILANI, Carlos Roberto Sanchez (Org.) Compreendendo a complexidade socioespacial contemporânea: o território como categoria de diálogo interdisciplinar. Salvador: EDUFBA, 2009. P.154.

14 Idem, Ibidem.

15 ETGES, V. E. O Programa de Pós-graduação em Desenvolvimento Regional da Universidade de Santa Cruz do Sul - UNISC. In: REDES, Santa Cruz do Sul, v. 8, n. 1, p. 57-69, jan./abr. 2003. P.67

16 BENKO, G. Economia, espaço e globalização na aurora do século XXI. $2^{\text {a ed. São }}$ Paulo: Hucitec, 1999. 


\section{Modelos alimentares dos romanos e dos bárbaros: algumas características e aspectos históricos}

A civilização romana originou-se a partir de uma pequena comunidade agrícola, na Península Itálica. A cidade de Roma, localizada na porção central desse território, surgiu por meio dos esforços dos povos latinos e sabinos que, por volta de 1000 a.C., estabeleceram um povoado no monte Capitolino, junto ao rio Tibre ${ }^{17}$.

Montanari ${ }^{18}$ afirma que os povos romanos não mostravam grande interesse pelas áreas de florestas. Formavam uma sociedade que sempre esteve ligada às práticas de produção agrícola e arboricultura, principalmente a cultura das oliveiras, sendo esses os principais eixos da sua economia. No cultivo de cereais, apostavam no trigo como um produto altamente valorizado, destinado às classes altas, no meio urbano. Os romanos designaram pejorativamente de bárbaros $^{19}$ os povos que não faziam parte do seu império, que não falavam a sua língua e "que não se dedicavam à agricultura, não comiam pão, nem bebiam vinho" 20 .

Segundo Freixa e Chaves $^{21}$, os romanos cultivavam as "oliveiras para obter a azeitona e o óleo de oliva; parreiras para a produção de vinho, e cereais para fazer o pão. Havia uma abundância de legumes, favas, feijões, lentilhas, tremoços, couve e rábano (raiz comestível)". As verduras e hortaliças constituíam os alimentos de base do camponês, juntamente com as frutas do tipo figo, ameixas e uvas.

17 PINHEIRO, K. A. de P. N. História dos hábitos alimentares ocidentais. In. Universitas Ciências da Saúde, Vol. 03, n.01, 2005, p. 173-190.

18 MONTANARI, M. A fome e a abundância: história da alimentação na Europa. Tradução: Andréa Doré. Bauru: EDUSC, 2003. p.18

19 Ao contrário de Flandrin e Montanari compartilhamos da ideia de Mota \& Braick que o termo bárbaro inicialmente tinha relação com "aquele que balbuciava (gaguejava)", isto é, aquele que tinha dificuldade para falar o idioma do império, o latim. Com o tempo teria havido um processo de ressignificação semântica onde o termo veio a assumir novo significado, mais pejorativo. MOTA, Myriam Becho. História: das cavernas ao terceiro milênio: Volume único/ Myriam Becho Mota, Patricia Ramos Braick. - 1. Ed. - São Paulo: Moderna, 1997.

20 FLANDRIN, J.-L.; MONTANARI, M. História da alimentação. 3. ed. São Paulo: Editora Estação Liberdade, 1998. p.111

21 FREIXA, D.; CHAVES, G. Gastronomia no Brasil e no mundo. 2. ed. Rio de Janeiro: SENAC Nacional, 2008. p.46 
A carne teve um papel importante na alimentação dos romanos, segundo Flandrin e Montanari ${ }^{22}$, principalmente devido à tradição "itálica" na criação de porcos. A utilização de carne bovina era rara e, quando consumida, era proveniente de animais velhos e fracos, que não eram mais úteis para o trabalho no campo ${ }^{23}$.

O pão, o vinho, o óleo de oliva, acompanhado de um pouco de carne de porco e, principalmente, pelos ricos queijos, complementavam os valores alimentares e caracterizavam o modelo alimentar chamado de mediterrâneo ${ }^{24}$. Esse modelo, segundo Flandrin e Montanari ${ }^{25}$, foi construído pela ideologia grega e romana, fundado sobre os três valores importantes "do trigo, da vinha e da oliveira (ou seja, do pão, do vinho e do azeite)", base de uma tríade de valores produtivos e culturais que aquela civilização tinha assumido como símbolos da própria identidade. Os romanos eram descritos como homens orgulhosamente ligados aos produtos da terra, alimentandose, por consequência, de uma ceia constituída por cereais, legumes, leguminosas, verduras, frutas e castanhas.

Os povos bárbaros, conforme Montanari ${ }^{26}$, eram as populações celtas e germânicas que, durante séculos, estavam habituados a percorrer as grandes florestas das regiões norte e central da Europa, na época do Império Romano. Os rios Reno e Danúbio eram as fronteiras que separavam as cidades romanas das zonas habitadas pelos bárbaros. Esses povos viveram em relativa harmonia com os romanos, até os séculos IV e V da nossa era, chegando, até mesmo a realizar trocas e comércio com os romanos, através das fronteiras.

Os bárbaros eram constituídos de tribos nômades que praticavam o pastoreio e a agricultura itinerante. Seus principais alimentos eram a carne, o leite e os queijos. É característica dos povos bárbaros a exploração das terras não cultivadas, das florestas, a prática da caça, da pesca e a coleta de plantas silvestres, sendo que 
estas tornaram-se as atividades centrais e características do seu sistema de vida ${ }^{27}$.

Montanari ${ }^{28}$ destaca que, nessa civilização, nem o pão, nem o vinho e nem a polenta foram elementos centrais da alimentação; mas sim a carne, sendo que a abundância deste ingrediente caracterizavase como o item de valor alimentar de maior importância. Esses povos não bebiam vinho, mas sim leite e líquidos ácidos que dele derivavam. Segundo ele, outras bebidas advindas de processos de fermentação, como a cerveja e a cidra, nos locais onde se cultivam cereais e nos bosques, tornaram-se bebidas muito apreciadas por esses povos. O autor complementa essa informação, indicando que a utilização de manteiga e toucinho era fortemente marcada no regime alimentar desses povos, assim como o consumo de cereais, mingaus de aveia e o pão de cevada, diferentemente dos produtos que faziam parte preponderante da alimentação dos romanos.

Carneiro $^{29}$ afirma que "o pão branco tinha se tornado o alimento mais típico da alimentação mediterrânica". Já o pão dos bárbaros - povos celtas e germânicos - era um pão de cor preta, de sabor mais marcante e denso. Item produzido a partir do centeio que, de acordo com Carneiro ${ }^{30}$, era "o único cereal panificável além do trigo, usado para produzir pão preto, identificado com os povos bárbaros, nórdicos e pobres".

A carne de porco, conforme Montanari ${ }^{31}$, tornou-se o ingrediente alimentar por excelência, sempre presente nas mais diferenciadas modalidades de preparação; ora assada, cozida, ao forno ou ensopada, foi a protagonista indispensável onipresente nos dois principais modelos alimentares europeus, seja na civilização bárbara, seja na romana.

Montanari $^{32}$ acrescenta que a alimentação dos diferentes povos era organizada, na maioria das vezes, da mesma forma, mas é importante considerar "o papel específico de cada produto no regime

27 Idem, Ibidem.

28 Idem, Ibidem.

29 CARNEIRO, Henrique S. Comida e sociedade. Uma história da alimentação. Rio de Janeiro-RJ: Campus, 2003. P.55.

30 Idem, p.56.

31 Idem, Ibidem.

32 Idem, p. 20 . 
alimentar, a posição e a importância que cabia a cada um no interior de um sistema que se organizava como uma unidade coerente, de modo diferente em cada caso".

Fica evidente que a história das civilizações tem um papel decisivo no processo de formação e definição de modelos alimentares, destacando-se o cristianismo como elemento fundamental na disseminação, por toda a Europa, dos hábitos alimentares baseados na tríade pão, vinho e óleo, alimentos que caracterizam o modelo alimentar mediterrâneo.

Destaca-se, dessa maneira, que os hábitos alimentares têm raízes profundas na identidade social dos indivíduos. Flandrin e Montanari $^{33}$ assinalam que Romanos e Bárbaros representavam, respectivamente, a civilização da agricultura contra a da exploração de florestas, do pão contra a da carne, do leite contra a do vinho, da manteiga contra a do óleo, do doméstico contra a do selvagem. E é com essas oposições, com modelos de produção e de consumo divergentes, que começará, no início da Idade Média, uma nova fase da história da alimentação e da cultura alimentar.

\section{Culinária regional: cereais, pães, bolos e biscoitos}

Segundo Knigh ${ }^{34}$, "o trigo foi introduzido no Rio Grande do Sul em 1749 pelos colonos vindos dos Açores". Conforme destaca Roche $^{35}$ "o trigo foi cultivado em primeiro lugar pelos colonos desejosos de afirmar a superioridade de sua condição, comendo pão branco" [...] que "cedo declinou, pois essa cultura oferecia muitas possibilidades, mas não lucros suficientes para atrair agricultores". O autor ainda complementa que "quase não se produz trigo nas colônias 
alemãs, onde o milho o suplantou na fabricação do pão cotidiano"36. Já a introdução da cultura do trigo nas colônias italianas ocorreu nos últimos anos do século XIX, conforme destaca Roche ${ }^{37}$. Entretanto, o trigo jamais se constituiu em um produto importante, pois não trouxe a contribuição que o estado esperava.

Roche $^{38}$ afirma que "o centeio fora associado ao trigo pelos primeiros colonos, que de início, se alimentavam do "pão alemão", ou pão misto (trigo e centeio em partes iguais). Mas uma série de más colheitas fê-lo desaparecer diante do milho". Sobre esse tema, Heinzelmann $^{39}$ relata que na Alemanha, principalmente nas regiões central e do norte, era muito comum o consumo de milho e centeio, sendo que este último era considerado anteriormente como uma erva daninha; com o tempo, esses grãos juntaram-se a vários outros tipos como de trigo e cevada. Sobre esse assunto, Bender ${ }^{40}$ uma das entrevistadas, que frequentemente visita a Alemanha, destaca que "na Alemanha os alemães estão acostumados com centeio, aqui quando chegaram a partir de 1824 tiveram que se adaptar principalmente e, por vezes, somente com o milho".

O uso do milho fica evidente ao longo da pesquisa, pois nas famílias de origem alemã, o uso de farinha de milho na preparação de alimentos do dia a dia era muito comum, tanto no preparo de pães quanto no de biscoitos, waffle e bolinhos. Na falta do tradicional pão de milho no café da manhã e/ou da tarde, era substituído por bolinhos ou waffle de farinha de milho.

O waffle é preparado a partir de uma massa de farinha e ovos, prensada em uma forma de ferro que, ao fazer a cocção no fogão à lenha, imprime texturas sobre a massa. Era muito comum nos cafés, quando havia a falta do pão, "antigamente também aqui em casa a

36 Idem, ibidem.

37 Idem, ibidem.

38 Idem, p. 246.

39 HEINZELMANN, U. Food culture in Germany - Food culture around the world. British Library, 2008.

40 BENDER, L. Práticas alimentares de descendentes alemães. Entrevista concedida ao autor em 10-03-2014. Santa Cruz do Sul, residência da entrevistada, 2014. 
mãe ou a vó faziam os waffles no fogão a lenha, a massa era feita à base de milho" ${ }^{\prime 4}$.

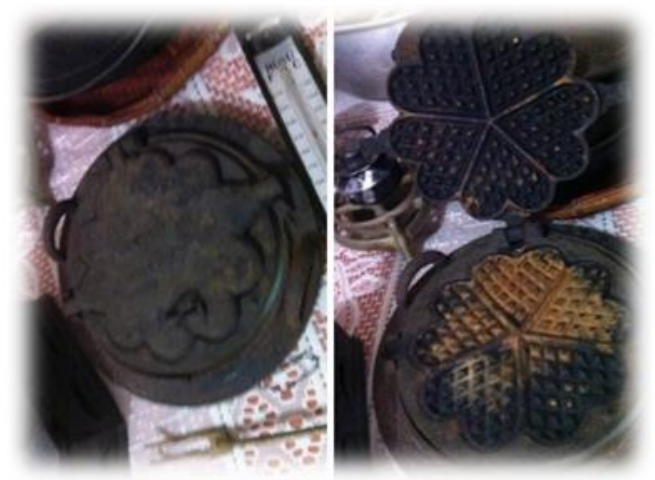

Forma de preparação de Waffle para fogão à lenha Fonte: Simon, 2014, p 56.

A farinha de milho também era muito utilizada pelos alemães para auxiliar a secagem da massa caseira, que era o tradicional prato dos domingos. Fülber ${ }^{42}$ esclarece o motivo da utilização da farinha de milho em substituição à farinha de trigo. Segundo ela, "a farinha de trigo naquela época era um produto muito caro, quando se usava muita farinha de trigo era somente nas festas de natal, páscoa, comunhões, aniversários, onde a mãe e a avó faziam cuca, bolo, bolachas".

\section{Grãos versus preparações}

\begin{tabular}{|c|c|}
\hline Farinha de trigo & Farinha de milho \\
\hline $\begin{array}{l}\text { Somente em datas especiais (Pães, } \\
\text { cucas, bolos e biscoitos). }\end{array}$ & $\begin{array}{l}\text { Pães, waffle, bolos e } \\
\text { bolinhos. }\end{array}$ \\
\hline $\begin{array}{l}\text { Uso do trigo e do milho na alimentação d } \\
\text { Fonte: Simon, 2014, p. } 57 \text {. }\end{array}$ & nães \\
\hline
\end{tabular}


Entre os italianos, há de se considerar, conforme De Boni ${ }^{43} \mathrm{o}$ milho foi, junto com o trigo, um produto muito importante, principalmente no que tange à alimentação; graças ao seu cultivo e à produção de farinha nos moinhos espalhados pelos vilarejos, havia a tradicional polenta e o pão de milho, quando faltava o trigo.

$\mathrm{Na}$ agricultura, o cultivo se destacava principalmente em virtude do milho ser um elemento com várias destinações, que ia muito além da presença na alimentação humana. Com o milho, alimentavam-se os animais de trabalho e de leite, tratavam-se as galinhas e engordavam-se os porcos, dos quais se obtinha banha, torresmo, morcelas (ou morcilhas, como também são chamadas nas colônias), além de linguiças, copas, salames, entre outros produtos. Enfim, o milho era o principal responsável pela geração de renda, quando a terra lhes proporcionava bons excedentes.

Os hábitos de consumo do milho, por parte dos italianos, verificados nas conversas, já diferem, se comparados aos dos alemães, pois nos seus hábitos alimentares há a presença dos dois tipos de farinha; entretanto, elas aparecem em preparações completamente diferentes no cotidiano das famílias. É possível visualizar essa diferença na tabela a seguir:

\begin{tabular}{|c|c|}
\hline \multicolumn{2}{|c|}{ Grãos versus preparações } \\
\hline Farinha de trigo & Farinha de milho \\
\hline $\begin{array}{c}\text { Pão branco, cuca alta, bolos e } \\
\text { biscoitos. }\end{array}$ & Polenta, pães. \\
\hline
\end{tabular}

Alguns entrevistados, de ascendência italiana, também destacam a utilização da farinha de milho na preparação de pães, conforme descreve De Boni ${ }^{44}$ e o relato da entrevistada Tolotti ${ }^{45}$ : "o

43 DE BONI, L. A.; COSTA, R. Far la Mérica: a presença italiana no Rio Grande do Sul = Making it in America: the italian presence in Rio Grande do Sul. Porto Alegre: RIOCELL, 1991.

44 Idem, Ibidem. 
trigo era plantado na propriedade e moído lá em casa mesmo, na falta dele a mãe incorporava ao pão um pouco de farinha de milho", produzindo assim o pão misturado, comum também nas regiões alemãs.

De acordo com os relatos dos entrevistados, o pão dos descendentes de alemães era principalmente o pão de milho. Entretanto, quando possível era incorporado um pouco de farinha de trigo, originando o pão misturado, com uma textura mais macia e um pouco mais leve se comparado ao de milho. Os pães de milho eram produzidos para dois ou três dias, sempre assados em forno à lenha; e era considerado um alimento de todos os dias nas famílias alemãs.

Outro tipo de pão consumido pelos colonos alemães na região era o elaborado com centeio, conforme destaca Roche ${ }^{46}$. Nos primeiros anos na colônia, o pão de centeio era muito produzido; entretanto, com as más colheitas do grão, ele acabou sendo substituído pelo pão de milho. Segundo relato da entrevistada Seibert $^{47}$,

Sempre caseiro - milho era o ingrediente principal, depois foram adicionando o trigo para deixar o pão mais leve, e mais tarde foram incorporando centeio às vezes. Nós plantávamos o milho e o melhor nós levávamos ao moinho para fazer farinha, em cada canto aqui da localidade tinha um moinho. A farinha naquela época era muito melhor.

O pão de trigo, conforme a figura 5 , geralmente sovado e de cor clara, tem presença maior nos relatos dos entrevistados de descendência italiana. Cortonesi ${ }^{48}$ descreve que, em toda a Itália

45 TOLOTTI, I. Práticas alimentares de descendentes italiano. Entrevista concedida ao autor em 23-02-2014. Santa Cruz do Sul, residência da entrevistada, 2014.

46 Idem, ibidem.

47 SEIBERT, G. Práticas alimentares de descendentes alemães. Entrevista concedida ao autor em 16-03-2014. Vale Verde, residência da entrevistada, 2014.

48 CORTONESI, A. "Cultura de subsistência e mercado: a alimentação rural e urbana na baixa Idade Média". In: FLANDRIN, J.-L.; MONTANARI, M. (Orgs.). História da Alimentação. São Paulo: Estação Liberdade, 1998. 
meridional e em grande parte dos campos comunais, o pão branco, elaborado a partir da farinha de trigo, é o alimento de base dos mais humildes trabalhadores da terra, bem como dos habitantes das áreas urbanas da Itália.

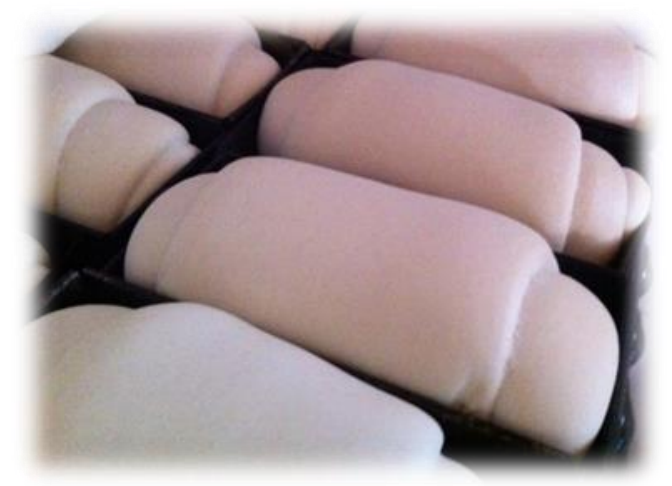

Pão Italiano de trigo sovado

Fonte: Simon, 2014, p. 59

É importante considerar que, conforme relatos, o pão de trigo para os alemães era um alimento especial, pois era preciso adquirir trigo, e comprar, conforme já mencionado, era um termo, e também um ato, não muito comum nas colônias. Dessa forma, obter o trigo e produzir produtos com sua farinha, acontecia somente nas festas ou datas muito especais. $\mathrm{O}$ uso cotidiano e abundante da farinha de trigo nas colônias de descendentes alemães tinha um significado de classe social diferenciada. Bender ${ }^{49}$, em seu relato, afirma que:

O pão de farinha de trigo era mais utilizado em eventos muito especiais, porque tinha que se comprar a farinha, e era muito cara na época. Comprar era uma palavra meio que estranha no vocabulário da família no interior, e não só da minha família, mas no interior como um todo. Fazia-se tudo em casa, adquiria-se só em casos extremos.

49 Idem, ibidem. 
Azambuja ${ }^{50}$ destaca que "quando uma visita ou aniversário se anunciava, assava-se cuca de açúcar, cuca recheada e enrolada, amanteigados recheados com canela ou bolachinhas diversas que eram guardadas em latas para a visita imprevista". Azambuja ${ }^{51}$ complementa que "os aniversários raramente eram comemorados com muitos convidados. $\mathrm{O}$ que não significava que o evento não fosse muito significativo para a família".

No que se refere à cuca, percebe-se que ela era quase exclusivamente relaciona a data especiais: "os aniversários eram café com cuca", comenta Seibert. A cuca tradicional era sempre a de farofa de açúcar (Streussel) ou também a de requeijão (Kässchmier) como é possível compreender nos relatos abaixo de Rauber ${ }^{52}$.

Cucas assim como posso dizer... principalmente a cobertura são muitas que podem ser, e assim no início que as minhas antepassadas e tuas também, vieram pra cá e então elas encontraram muitas frutas aqui e em toda região, então elas começaram a adaptar a cobertura com essas frutas, elas faziam doce de frutas e colocavam em cima da cuca, mas geralmente sobre a cuca vai o nosso Streussel. O Streussel é quase que característico". Kässchmier kuchen era muito feito na colônia também, porque quando sobrava leite, as colonas preparavam o Kässchmier.

Bender ${ }^{53}$ corrobora ao afirmar: "o meu aniversário era cuca, desde a mais remota lembrança, era cuca, não havia festa, não havia presente, mas havia cuca". A entrevistada complementa essas informações, relatando sua percepção em relação às diferenças entre

50 AZAMBUJA, Lissi Bender (Org.). Forno e fogão: como no tempo de nossos avós = Kochen und Backen : Wie Unsere Grosseltern. Santa Cruz do Sul: EDUNISC, 1999. P.23.

51 AZAMBUJA, Lissi Bender (Org.). Forno e fogão: para dias festivos = Kochen und backen für feierliche tage. Santa Cruz do Sul: EDUNISC, 2001. P.29.

52 RAUBER, G. Práticas alimentares de descendentes alemães. Entrevista concedida ao autor em 09-04-2014. Santa Cruz do Sul, residência da entrevistada, 2014.

53 Idem, ibidem. 
as cucas dos alemães da atual Alemanha, dos descendentes aqui da região e a dos italianos conforme figura 6 :

A diferença que eu percebo entre as cucas alemãs e italianas está relacionada à altura da massa da cuca italiana, que é tipo pão e com a farofa por cima, e eles chamam isso de cuca. A alemã tem a massa baixinha e não é seca, a Italiana é uma massa seca. A alemã tem uma cobertura generosa, é diferente, a massa é feita com fermento biológico e é muito comum no norte da Alemanha, é de lá que ela veio, do nordeste; dizem as pesquisas que a cuca de açúcar veio da Silésia, que já foi alemã, e não é mais hoje. As cucas do norte são sempre com cobertura de frutas da estação. [...] E no sul da Alemanha é mais comum ver a cuca feita com fermento químico, a cuca rápida que eles também chamam de bolo, e também aquela feita com massa podre, que fazem só aquele fundo e a beirada da forma e depois colocam aquele recheio todo lá dentro. Kässküchen é diferente da nossa, a dos alemães é feita com massa podre.

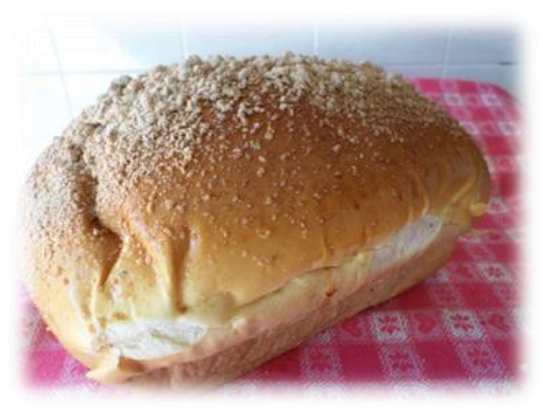

Cuca italiana

Fonte: Simon, 2014, p. 61.

A tradicional cuca dos alemães, com o passar do tempo, foi sofrendo alterações no seu modo de preparo. Do tradicional de açúcar (Streussel), hoje as cucas são produzidas com vários recheios, de quase todos os tipos de frutas, e tantos outros recheios inusitados 
como, por exemplo, da famosa cuca de açúcar com linguiça. A iguaria, apresentada em diferentes versões e com variados sabores, é também um atrativo turístico reconhecido em todo o estado. A Festa das $\mathrm{Cucas}^{54}$, que se iniciou em 2001 e chegou em 2014 na sua $14^{\mathrm{a}}$ edição, consolida-se como o segundo maior evento no município de Santa Cruz do Sul, depois da Oktoberfest. Durante a festa, são comercializadas em torno de 18.000 unidades de cucas, além de produtos coloniais dos produtores do município.

Alguns desses novos sabores, ainda que reinventados, passam de geração em geração, sempre mantendo a sua essência. Nos municípios de colonização alemã, as cucas tradicionais, "modernas", enroladas e rápidas são as deliciosas e tradicionais companhias das famílias da região; a cuca de açúcar (Streussel), por exemplo, afirmam Azambuja e Heinle ${ }^{55}$, é a "rainha entre a imensa variedade de cucas produzidas nas regiões de colonização alemã".

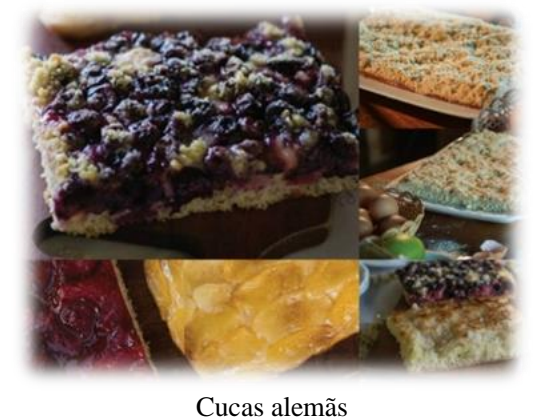

Fonte: Festa das Cucas 2014. Foto extraída de Simon (2014, p.62)

Outra preparação que os colonos de origem alemã entrevistados destacaram foi a cuca de melado. A cuca de melado é uma adaptação da cuca de mel, muito comum entre eles.

54 FESTA DAS CUCAS. Disponível em: http://www.festadascucasrs.com.br. Acesso em: Ago. 2014.

55 AZAMBUJA, Lissi Bender; HEINLE, Sabine (Org.) Receitas do Sul - Brasil e Alemanha (Rio Grande do Sul / Baden-Württemberg) = Rezepte aus dem Süden - Brasilien und Deutschland (Rio Grande do Sul / Baden-Württemberg). Santa Cruz do Sul: EDUNISC, 2004. P. 69. 
Já para os italianos, a cuca tradicional é a cuca alta, "que é um pão alto com farofa de açúcar por cima", relata Raminelli ${ }^{56}$. Essa cuca de massa doce e com adição de ovos é finalizada com farofa por cima e é chamada de cuca na região serrana do Vale do Rio Pardo, em que predominam os descendentes de italianos.

A partir dos dados coletados nas entrevistas, percebe-se que, mesmo nos municípios de descendência italiana, a cuca alemã se sobressai em relação a tradicional cuca alta, pois segundo Ceretta ${ }^{57}$,

A cuca a gente faz, mas não seguido, mas eu já faço a baixa, que eu prefiro. Agora já nem se faz mais daquela alta com farofa por cima, aqui em casa a gente só faz as baixinhas, com recheio de uva, coco, abacaxi.

A produção de biscoitos também é muito comum nos municípios visitados. Silva ${ }^{58}$ destaca que a "bolacha de natal", também chamada de Teegebäck, e os docinhos específicos eram sempre produzidos em datas especiais, como as festas de final de ano. Além destes, eram muito comuns, nas regiões de descendentes de alemães, os biscoitos tradicionais à base de manteiga e também os Spekulatius, que eram elaborados com farinha de trigo e manteiga. Entretanto, eles eram aromatizados com especiarias do tipo canela, cravo e noz moscada, preparados para acompanhar o chá ou o chimarrão dos finais de semana, principalmente quando se recebia uma visita. Azambuja ${ }^{59}$ ressalta que "na Alemanha a tradição na confecção de doces natalinos se mantém viva e é carinhosamente cultivada".

56 RAMINELLI, M.. Práticas alimentares de descendentes italiano. Entrevista concedida ao autor em 22-03-2014. Arroio do Tigre, residência da entrevistada, 2014.

57 CERETTA, V. DE B. Práticas alimentares de descendentes italianos. Entrevista concedida ao autor em 22-03-2014. Sobradinho, residência da entrevistada, 2014.

58 SILVA, M. C. G da. O impacto da imigração europeia sobre a produção de alimento e a culinária do médio Vale do Itajaí, SC In: Desafios contemporâneos/organizadores Manuel Ferreira Lima Filho, Jane Felipe Beltrão, Cornelia Eckert. Blumenau: Nova Letra, 2007.

59 Idem, p. 19. 
Em relação aos biscoitos, Frey ${ }^{60}$ destaca que "os biscoitos eram preparados quase sempre em datas especiais como final de ano, e eram os de manteiga, ou aqueles tradicionais de natal pintados com glacê". Nas famílias de descendentes de italianos, os biscoitos de natal cobertos com glacê também eram muito comuns. Raminelli ${ }^{61}$ destaca que:

A gente fazia aquela bolacha bem comum de natal que a gente passava açúcar, canela e ovo por cima da massa e assava. Somente para o natal que a gente comprava o açúcar normal para fazer bolacha, nos demais dias do ano as preparações eram usadas apenas o açúcar mascavo.

A produção de pães e de cucas são elementos característicos que distinguem as duas etnias pesquisadas. A produção desses itens estava condicionada ao uso do fermento biológico - Saccharomyces cerevisiae, ingrediente importante, pois este elemento é o responsável para que a massa fique leve e macia. Dettemborn ${ }^{62}$ relata que "antigamente não se comprava esses fermentos que hoje temos à disposição no mercado", ele era produzido em casa, e sua forma de produção variava de família e região, conforme relatos. Kroth ${ }^{63}$ complementa que,

Quando a gente fazia pão o fermento era sempre feito em casa, com farinha de milho, mas eu não sabia fazer, pois tinha uma vizinha que fazia e ela não falava como, sabe tipo mantinha em segredo. Quando terminava o nosso fermento, tinha a nossa vizinha lá no cerro que fazia, eu lembro que minha mãe pedia para eu ir buscar, mas ela

60 FREY, T.T. Práticas alimentares de descendentes alemães. Entrevista concedida ao autor em 12-04-2014. Linha Áustria - Santa Cruz do Sul, residência da entrevistada, 2014.

61 Idem, ibidem.

62 Idem, ibidem.

63 KROTH, E.L.. Práticas alimentares de descendentes alemães. Entrevista concedida ao autor em 10-04-2014. Cerro da Boa Esperança - Passo do Sobrado, residência da entrevistada, 2014. 
nunca dizia como ela fazia, eu só me lembro que eu tinha que ir lá na casa dela pegar, os colonos tudo lá faziam com esse fermento dela, as cucas e os pães eram todos feitos com o fermento dela.

Ebert $^{64}$, moradora de outra colônia alemã, relata que em sua casa o fermento também era produzido artesanalmente, mas lembra que era feito com uma espécie de mistura de farinha de milho e água:

E então botava no sol, mas só colocava água e aí começava a fermentar ali mesmo no sol, nós não tínhamos condições de comprar o fermento pronto, era caro, então era o que a gente fazia. Depois de pronto guardava num vidro fechado e pegava quando precisava.

Nas famílias de origem italiana, percebeu-se que as trocas de fermentos também promoviam a socialização e a reciprocidade entre as famílias entrevistadas. Fardin Ceretta ${ }^{65}$ relata o processo de elaboração artesanal do fermento:

Assim... tu rala uma batatinha, e bota três colheres de farinha, duas de açúcar e uma de sal, e tu completa o vidro com água, e isso fica na geladeira bem embaixo. $\mathrm{E}$ no dia que tu vai fazer o pão tu tira de manhã da geladeira, e daí tu renova ele (o fermento né), tu rala mais duas batatinha, coloca mais farinha, mais açúcar e sal ali e completa de água. E daí de noite tu aumenta aquilo com um quilo de farinha, mas, reserva um pouco sempre né, para ter o fermento vivo. Isso faz uma massa mole, e deixa crescer a noite inteira. Daí no outro dia você faz o pão, coloca os outros ingredientes, é melhor

64 EBERT, H. Práticas alimentares de descendentes alemães. Entrevista concedida ao autor em 13-04-2014. Linha Áustria - Santa Cruz do Sul, residência da entrevistada, 2014.

65 CERETTA FARDIM, M.A. Práticas alimentares de descendentes italianos. Entrevista concedida ao autor em 22-03-2014. Ibarama, residência da entrevistada, 2014. 
de manhã e deixar crescer, pois o processo é mais lento, mas o sabor fica bem melhor, lá em casa antigamente a mãe fazia só dessa forma.

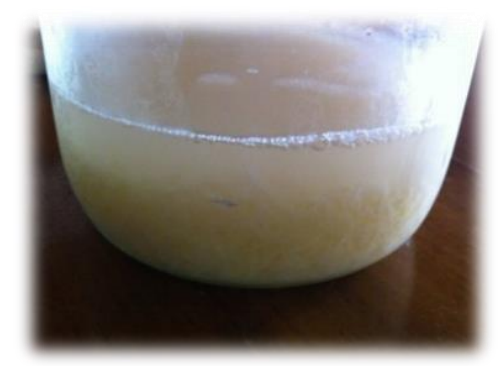

Processo de fermentação com batata inglesa Fonte: Simon, 2014, p. 64.

O fato curioso é que o fermento era, e é ainda hoje, elaborado pelas senhoras, entretanto, com ingredientes e procedimentos diferentes, se comparados aos das famílias alemãs. Entre os descendentes de italianos, ele é preparado a partir do uso da batata inglesa em um processo de fermentação.

\section{(Re)considerações Finais}

A alimentação torna-se um dos principais componentes da etnicidade e está fortemente ligada aos fatores culturais. Além de toda sua roupagem de calorias, proteínas e carboidratos, nela é possível encontrar um universo de significados, de representações e de história.

A produção e o consumo de pães são elementos da cultura alimentar da Região do Vale do Rio Pardo que manifestam, segundo Simon(2014), a presença de características dos modelos alimentares "romano" e "bárbaro". Particularidades desses modelos, segundo o 
autor, estão presentes nos hábitos dos colonos alemães e italianos que compuseram o grupo estudado.

$\mathrm{Na}$ transição da antiguidade para o medievo, o pão branco tinha se tornado o alimento mais típico da alimentação dos povos romanos, enquanto o pão de cor mais escura, de massa densa e com sabor marcante, era considerado o pão dos bárbaros - povos celtas e germânicos. Ingredientes, saberes e formas de preparo constituíramse em elementos que distinguiram os dois modelos alimentares na Europa.

As reflexões realizadas recentemente a respeito da temática permitiu-nos reconsiderar algumas questões sobre a abordagem e as conclusões apresentadas por Simon.

A análise realizada nesse momento, sobretudo a respeito do consumo de cereais e derivados, permite relativizar a identificação de que os imigrantes trouxeram e difundiram características e influências dos modelos alimentares estudados. Embora sejam vetores de cultura e tradição, não é possível explicar a permanência e transmutação de determinadas características dos modelos bárbaro e romano apenas a partir da imigração alemã e italiana no sul do Brasil. Se assim fosse, tais elementos teriam se estruturado num tempo de longa duração, o que não é possível afirmar. A literatura disponível hoje no campo da História da Alimentação possibilita maior amadurecimento a respeito desse tema, permitindo-nos inferir que muitas das características dos costumes alimentares presentes nesses modelos também podem ser encontradas em hábitos alimentares do Mediterrâneo que já haviam sido trazidos ao Brasil nos primeiros anos de colonização portuguesa.

A presença de características desses modelos nos costumes de alemães e italianos na Região do Vale do Rio Pardo não deve ser vista na perspectiva de uma permanência que teria subsistido a uma transposição de tempo e espaço. A identificação dessas características na culinária regional de colonos alemães e italianos no Sul do Brasil deve ser vista na perspectiva de um processo complexo e intercultural que não se reduz aos modelos alimentares romano e bárbaro, mas, sim, que ocorre em diferentes dinâmicas de integração e adaptação.

Desse modo, o pão elaborado a partir da farinha de trigo e dos saberes e formas de preparo, tornam-se elementos característicos dos descendentes de italianos, na região do Vale do Rio Pardo. Já os 
saberes e práticas relacionados à elaboração dos pães de cor escura, preparados a partir de grãos do tipo centeio, pão característico do modelo bárbaro, também era comum, entre as colônias alemãs nos primeiros anos de colonização. Entretanto, dentre as causas e processos plausíveis a respeito das adaptações, vimos que problemas relativos às más colheitas e à falta do cereal também explica a adaptação/substituição dos colonos alemães à cultura do milho.

As particularidades desse processo são de grande relevância para a compreensão da configuração dos costumes alimentares da região do Vale do Rio Pardo. No sul do Brasil, reprodução e adaptação, permanência e transformação, coexistem e se entrecruzam no que diz respeito à constituição e caracterização das culinárias regionais.

RECEBIDO EM: 15/05/2016 APROVADO EM: 25/06/2016 